\title{
Editorial: Message from the Incoming Editor
}

\author{
Miguel Alonso ${ }^{1,2, *}$ \\ ${ }^{1}$ Aix-Marseille University, CNRS, Centrale Marseille, Institut Fresnel, UMR 7249, 13397 Cedex 20, France \\ ${ }^{2}$ The Institute of Optics, University of Rochester, Rochester, New York 14627, USA \\ *Corresponding author: miguel.alonso@fresnel.fr
}

Received 8 January 2020; posted 8 January 2020 (Doc. ID 387852); published 15 January 2020

\begin{abstract}
Miguel Alonso, beginning his term as Editor-in-Chief, looks forward to continuing Optics Letters' tradition of serving the optics and photonics community and publishing high-impact short communications. (๑) 2020 Optical Society of America
\end{abstract}

https://doi.org/10.1364/OL.387852

It is both an immense honor and a great responsibility for me to become the eighth Editor-in-Chief of Optics Letters, following in the footsteps of Bob Terhune (1977-1983), Paul Kelley (1984-1989), Peter Smith (1990-1995), Anthony Johnson (1996-2001), Anthony Campillo (2002-2007), Alan Willner (2008-2013), and Xi-Cheng Zhang (2014-2019). Since its inception in 1977, Optics Letters has been the preferred venue for short communications reporting on important results over all areas of optics and photonics, both fundamental and applied.

Not only are optical science and technology advancing at a vertiginous pace these days, but scientific publishing itself is also rapidly evolving, with new journals and other forms of publication appearing constantly. Keeping up with these changes presents important challenges. However, I believe that the strength of Optics Letters stems from its reputation as a prestigious publication, for and by active researchers, where the quality of the research is the main criterion. Another very positive change taking place is the trend towards a larger, more diverse scientific community that is more fairly representative of the wider society. One of my personal goals is to help promote this diversity, which should be reflected in the Journal's Editorial Board.
Under Xi-Cheng Zhang's leadership, Optics Letters has continued to flourish and grow, so I am very fortunate to take over a very healthy journal. The Editorial Board is currently composed of 59 hard-working Topical Editors, all of them renowned experts in their respective fields. I am particularly looking forward to working closely with our Features Editor, Andrea Armani, and our three Deputy Editors, Carsten Rockstuhl, Ed Whittaker and, for a few weeks, Andrea Galtarossa, who will be completing his second term at the end of January. He will be succeeded by William Shieh, who has served as Topical Editor for six years. My work and that of the Topical and Deputy Editors is greatly facilitated by the wonderful editorial team at OSA's headquarters, with whom I am also very excited to collaborate. However, the main piece in the fine-tuned machine that is Optics Letters is the optics and photonics community, who serve both as its authors and reviewers. Optics Letters relies on and is here to serve this community.

Miguel Alonso 